\title{
Hacia un liberalismo clásico como la defensa de la intimidad personal
}

\section{Gabriel Zanotti*}

Profesor de la Universidad Austral.

Argentina

\section{Resumen:}

Este ensayo intenta una nueva versión del liberalismo clásico que pueda ser considerada como una superación de dos posiciones antagónicas. Por un lado, la posición liberal clásica donde el famoso principio de "daño" de Mill es acompañada por cierto escepticismo moral en materias de moral personal. Por otro lado, una posición más tradicional basada en la ley natural, donde una moral objetiva debe ser tenida en cuenta, pero de tal modo que el resultado sea la intervención gubernamental. Proponemos entonces superar el debate utilizando el concepto clave de intimidad personal, como el núcleo central de un programa de investigación donde la libertad individual sea tan importante como nuestras obligaciones morales respecto de otras personas, la comunidad y el bien común.

Palabras clave:

Liberalismo clásico, ley natural, persona, intimidad.

\section{Abstract:}

This essay is an attempt to achieve a new version of classical liberalism, in such a way that could be considered a road beyond two opposite views. On the one hand, the classical liberal position in which the famous Mill's harm principle is taken along with certain kind of moral scepticism in matters of individual choices. On the other hand, a more classical natural law position, where we have to take care of the

* Este ensayo fue escrito en el primer semestre de 2005. Agradezco los comentarios recibidos antes y durante la reunión del Departamento de Investigaciones de Eseade, el 10 de Agosto del presente año, donde aportaron sus críticas y comentarios Martín Krause, Eduardo Stordeur, Eliana Santanatoglia, Cecilia Gianella, Constanza Mazzina, Adrián Ravier, Ricardo Lopez Gottig y Santiago Legarre. Me han hecho comentarios adicionales Juan Francisco Ramos Mejía, Mario Silar, y Roberto Bosca. Como es de rigor, los errores son sólo míos. 
objective moral choices of humane beings, in such a way the government intervention could be the result. So we propose to go beyond the debate using the key concept of personal intimacy as the hard core of a research program where the individual liberty is as important as our moral duties in relation to other people, community and the common good.

Key words:

Classical liberalism, libertarianism, natural law, humane person, intimacy.

\section{Introducción}

El presente artículo intenta presentar una tesis superadora de dos modos distintos de plantear la libertad individual, dentro de un paradigma que, de modo muy discutible, se podría llamar "la tradición liberalclásica/libertaria".

La clasificación que haremos ahora no pretende ser una más dentro de las ya tradicionales clasificaciones de corrientes de filosofía del derecho o de filosofía política. Nuestra intención es más bien describir modos de justificación de las libertades individuales que constituyen el núcleo central de la tradición liberal aludida. Para ello recurriremos al método del "autor-modelo", método que ya hemos utilizado en otra oportunidad ${ }^{1}$. Este método consiste en efectuar una descripción simplificadora de la posición de un autor, con el riesgo de borrar parte de la riqueza y sutileza de su pensamiento pero con la ventaja de convertir esta posición en un modelo abstracto donde, con matices, puedan entrar otros autores y corrientes de pensamiento.

La primera posición corresponde a lo que podríamos llamar "el modelo Mill-Hayek". En esta tradición, la libertad individual, concebida globalmente como el derecho a no ser coaccionado por terceros en los propios proyectos de vida, depende fundamentalmente de cierto nivel de incertidumbre en nuestro conocimiento. La pretensión de conocer con toda certeza la verdad llevaría a la coacción sobre el otro, mientras que el reconocimiento de nuestros límites de conocimiento nos abre a la tolerancia y al diálogo. Mill es un clásico al respecto ${ }^{2}$, pero autores como Popper ${ }^{3}$, Mises $^{4}$ y Hayek ${ }^{5}$ han sido interpretados de este $\operatorname{modo}^{6}$, con toda la influencia que han tenido en la tradición liberal clásica en el siglo XX. El último

${ }^{1}$ En (2004): “Igualdad y desigualdad según desiguales paradigmas”, Empresa y Humanismo, Vol. VII, núm. 2, pp. $259-254$.

${ }^{2}$ Nos referimos al clásico On Liberty, en Polanco, Moris (2001): 100 Books Of Philosophy, CD, Guatemala.

${ }^{3}$ Ver sobre todo (1971): Open Society and its Enemies, Princeton University Press.

${ }^{4}$ Ver sobre todo (1977): Liberalismo, Madrid: Unión Editorial; y (2003): Teoría e Historia, Madrid: Unión Editorial.

${ }^{5}$ Ver sobre todo (1975): Los Fundamentos de la Libertad, Madrid: Unión Editorial.

${ }^{6}$ Decimos "han sido interpretados" porque en el caso de Popper tenemos nuestras razones para pensar que no es así; al respecto, ver nuestro ensayo (1999): "Karl Popper: antes y después de Kyoto”, Arbor, núm. 642. pp. 229-243. 
Ralws, con su desarrollo de los elementos de un pacto político, no metafísico ${ }^{7}$, participa también en la misma tradición, si bien netamente separada de la misma por el tema del derecho de propiedad y redistribución de ingresos, donde había puesto su insistencia el primer Ralws ${ }^{8}$.

A su vez, en esta tradición, la libertad individual es vista fundamentalmente como negativa, como derecho a la ausencia de coacción, incorporando además el "harm principle" de Mill: uno es libre de hacer todo aquello que no afecte derechos de terceros. Siguiendo la línea de Hume, la moral es concebida sobre todo como una cuestión social, dejando las concepciones éticas "individuales" (precisamente, toda decisión que no afecte derechos de terceros) como creencias metafísicas privadas ("metafísica" como esta tradición, siguiendo a Kant, lo entiende) que no son socialmente relevantes.

La segunda concepción de libertad individual podría ser denominada "libertaria-Rothbard"'. En esta posición, la cuestión no pasa tanto por la limitación del conocimiento humano y menos aún por la no relevancia social de una moral individual. Al contrario, el axioma fundamental de sistema (es un modo de pensar deductivo, a priori, no histórico) es la posesión que la persona tiene de sí misma, esto es, una propiedad privada absoluta que la persona tiene de sí misma y por ende de todos los frutos de su acción libre y voluntaria. La moral objetiva pasa por respetar este axioma y sus consecuencias, una de las cuales sería el principio de no agresión, esto es, nadie tiene el derecho de iniciar la violencia contra un tercero, y tiene consiguientemente el derecho de legítima defensa contra una agresión tal. Por eso Rothbard reconoce a Locke como un antecedente evolutivo de su propia posición, le perdona relativamente su "confusión" respecto a ciertas cuestiones del derecho de propiedad, pero se distancia claramente de Nozick en la aceptación que este último tiene del estado mínimo: en este esquema, un gobierno liberal clásico al estilo mínimo, que cobrara impuestos compulsivamente, es indebido precisamente porque viola el principio de no agresión, y las argumentaciones de Nozick tipo mano invisible para justificar un gobierno así no convencen a Rothbard de ningún modo. No es objetivo de este artículo introducirnos ahora en el debate.

A su vez, entran en este esquema las argumentaciones de derecho natural, pero concebidas fundamentalmente como el derecho natural absoluto de propiedad como lo hemos descrito, con un esquema axiomático donde ese derecho es el axioma del sistema, sin ninguna necesidad de argumentación adicional en la teología o en la historia. Colocar a Santo Tomás de Aquino en esta tradición, como hace Rothbard, es en nuestra opinión erróneo, pero tampoco corresponde ahora introducirnos en este tema ${ }^{10}$.

\footnotetext{
${ }^{7}$ Me refiero a los libros (1993): Political Liberalism, Columbia University Press, y (1999) The Law of Peoples, Harvard University Press.

${ }^{8}$ Nos referimos al clásico (1971): A Theory of Justice, Harvard University Press.

${ }^{9}$ De Rothbard, ver (1985): For a New Liberty, Fox \& Wilkes; (1998): The Ethics of Liberty, New York University Press.

${ }^{10}$ En otras oportunidades hemos expresado nuestras propias opiniones respecto del fundamento de los derechos individuales; ver al respecto (1989): El humanismo del futuro Editorial de Belgrano, Buenos Aires. También, en otras oportunidades, hemos
} 
Ambas posiciones, a pesar de sus profundas diferencias, tienen un punto teorético (no me refiero a un resultado práctico) en común, que ha influído mucho el modo habitual de argumentar en lo que podríamos denominar los "ambientes" liberales y libertarios. La libertad personal es concebida moralmente como el derecho a hacer todo aquello que no perjudique derechos de terceros. O sea que, por un lado, la libertad personal no tendría límites morales mientras no afecte a terceros; a su vez, el único deber moral para con otras personas es no iniciar coacción sobre ellas. Esto es, el famoso principio de que la libertad personal termina donde comienzan los derechos de terceros, o que todo lo que no está prohibido (prohibición que se justifica tanto en el principio de no agresión rothbariano como del harm principle milliano) está permitido tiende a verse no sólo como un principio jurídico-positivo sino como un principio moral. Un resultado adicional de esto es que sería vista como peligrosa para la libertad individual y para el paradigma liberal/libertario cualquier posición filosófico-moral que establezca estas tres cuestiones: a) hay deberes morales personales que van más allá del sólo no agredir al otro; b) puede conocerse con certeza la verdad, sobre el punto a y sobre diversos temas metafísicos; c) para con el otro no sólo hay un deber moral de no agresión, sino sobre todo de cuidado, de preocupación, de diálogo, de ayuda, de amistad (amor benevolentiae), en última instancia, definido como querer el bien del otro.

La tradición liberal/libertaria, en última instancia, en su lucha contra diversos y terribles autoritarismos y totalitarismos del siglo XX, ha establecido para con el famoso "otro", tan caro a contemporáneas filosofías del diálogo ${ }^{11}$, una relación de indiferencia más que de cuidado. Mientras que el otro no moleste, no hay problema. "Es su vida". No decimos que esta tradición ignore o niegue la importancia de las relaciones familiares o amistosas intersubjetivas en pequeños grupos, y menos aún negamos que si las relaciones sociales humanas, tan laceradas por la violencia política, fueran al menos así, el mundo sería ya muy diferente al actual infierno en el que lo ha convertido la violencia antiliberal. Tampoco negamos, es más, nos hemos adherido ${ }^{12}$ a la tesis de Hayek cuando afirma que el eje central del problema social es el paso de pequeñas sociedades ("tribales") a la convivencia de millones y millones de personas bajo un marco de conocimiento disperso, convivencia que no puede basarse jurídicamente en los sentimientos de amistad que se dan en los pequeños grupos. Tampoco negamos, es más, hemos afirmado, que el eje central del problema político concreto consiste en la convivencia de los diferentes ${ }^{13}$, para lo cual la tolerancia mutua de los que Rawls llama doctrinas "comprensivas" ${ }^{14}$ es esencial. Lo que decimos es que es teoréticamente erróneo que la base del sistema liberal/libertario sea esa indiferencia hacia el otro,

hecho una intentio lectoris de la primer posición (en cuanto a Hayek y la escuela escocesa) donde ésta no es incompatible con la noción de ley natural en Santo Tomás; ver al respecto (2001): "La ley natural, la cooperación social y el orden espontáneo", Revista de la Facultad de Derecho, Universidad Francisco Marroquín, núm. 19, pp. 117-122.

${ }^{11}$ Nos referimos a Buber y Lévinas.

${ }^{12}$ Ver nuestra (2003): Introducción filosófica a Hayek, Guatemala/Madrid: Universidad Francisco Marroquín/Unión Editorial.

${ }^{13}$ En nuestra introducción a Mises, L. von (2003): Teoría e Historia, Madrid: Unión Editorial.

${ }^{14}$ Ver Political Liberalism, op.cit. 
independientemente de que, además, esa "base" (núcleo central) sea una de las causas por las cuales el "discurso" liberal clásico penetra poco en una opinión pública sanamente inclinada, a nuestro juicio, a la relación solidaria con el otro, al menos en el discurso. Pero si consideramos errónea dicha posición, no por ello se desprende (y aquí está la clave de nuestro ensayo) que la tradición liberal/libertaria, desde un punto de vista político y jurídico-positivo, sera errónea. Pero no sólo intentaremos demostrar que una ética de "cuidado por el otro" es "no contradictoria" con el liberalismo clásico, sino que es su mejor fundamento moral. Hecha esta audaz afirmación, pasemos a demostrarla.

\section{Derecho natural, propiedad de sí mismo y Dios}

Desde una perspectiva tomista del derecho natural ${ }^{15}$, el tema de la propiedad de sí mismo debe plantearse con sumo cuidado. Es verdad que es posible en Santo Tomás un tratamiento de la ley natural haciendo una especie de "epojé", desde un punto de vista metodológico, de Dios como causa primera. Esto es, desde Santo Tomás podría decirse que "la naturaleza humana" (él nunca lo dijo de ese modo) es el fundamento de tal o cual precepto moral, pero sería incompleto. Las causas "segundas" tienen autonomía porque son causas eficientes principales en su propio ámbito ${ }^{16}$, pero ello no implica dejar de lado a Dios desde un punto de vista de la argumentación racional, porque el creador y sostenedor en el ser de esas causas segundas eficientes es Dios, Dios que él considera posible de un tratamiento racional, tesis que yo he seguido defendiendo "a pesar de" las importantes advertencias kantianas ${ }^{17}$. Por ello no debemos tener ninguna sorpresa cuando su noción de ley natural aparece como "participación de la criatura racional en la ley eterna"18, haciendo referencia, con ley eterna, a Dios mismo. O sea que en Santo Tomás, el fundamento último de que haya ley natural es que Dios es la causa primera de todas las causas segundas.

Por consiguiente, desde una perspectiva tomista del derecho natural, no podría afirmarse que todo ser humano sea dueño absoluto de sí mismo, sencillamente porque no es creador de sí mismo. Dios da el ser a todo lo creado, y Dios lo quita. O sea que no podemos reclamar propiedad de aquello que radicalmente no viene de nosotros mismos, y, por el mismo motivo, Dios es nuestro dueño. Todo esto, que Santo Tomás puede demostrar en una razón en diálogo con la $\mathrm{fe}^{19}$, muestra la coherencia racional de las diversas religiones que llaman a Dios "el Señor": él tiene el dominio. Esta conclusión, que rasgará las vestiduras de algunos esquemas libertarios, la decimos precisamente porque es esencial para la tesis anunciada en el punto uno.

\footnotetext{
${ }^{15}$ Por "tomista" entendemos "filosofía de Santo Tomás" y no tal o cual escuela tomista.

${ }^{16}$ ST, I, Q. 2, a. 3 ad 1.

${ }^{17}$ En nuestra (2003): Filosofía para filósofos, Madrid: Unión Editorial, cap. 9.

${ }^{18}$ I-II, Q. 91, a. 2c.

${ }^{19}$ Sobre el tema diálogo razón/fe, ver Sciacca, M.F. (1954): Historia de la filosofía, Barcelona: Luis Miracle; y la enc. Fides et ratio de Juan Pablo II.
} 


\section{Inteligencia, voluntad y verdad}

A su vez, esta ética y esta filosofía del derecho tiene una antropología filosófica implicada en la definición "participación de la creatura racional en la ley eterna". Después de Kant hay que explicar nuevamente qué significa en Santo Tomás "racional”.

Inteligencia significa una capacidad de contemplar limitadamente la naturaleza de la realidad ${ }^{20}$, que incluye, desde luego, la conciencia de sí $\mathrm{mismo}^{21}$, pero no como primer principio ni punto de partida de la filosofía. Una función de la inteligencia, concebida así como "intelligere" es la "ratio", como capacidad de razonamiento ${ }^{22}$. O sea que la inteligencia no es ante todo el razonamiento sino la capacidad de contemplación teorética de lo real, que incluye el razonamiento pero que no se reduce a él. Esta noción de inteligencia como contemplación fue rescatada luego por E. Husserl ${ }^{23}$ y constituye uno de los puntos básicos de encuentro entre la fenomenología y la tradición clásica ${ }^{24}$.

De la capacidad de contemplación de lo real, aunque limitada, surge el libre albedrío como libre juicio de la razón ${ }^{25}$, o como elección de bienes limitados ${ }^{26}$. Este no es un tema menor, si luego se afirma que "el individuo" es sujeto de libertades individuales. Tampoco es un tema menor cuando se quiere hacer una epistemología de las ciencias sociales no positivista, basada en una noción intencional de acción humana ${ }^{27}$. En gran parte de los autores anteriormente citados (no por supuesto en neoaristotélicos como Rothbard) la libertad individual es afirmada por elementos que nosotros no sólo no hemos negado sino enfáticamente afirmado (como es el caso de la cooperación social y el orden espontáneo ${ }^{28}$ ), pero por un obvio y comprensible efecto filosófico de cierto neokantismo, la noción de persona como sujeto de derechos queda envuelta en un manto de sombras o descartado como un tema "metafísico". La

${ }^{20}$ Ver al respecto Ferro, L.S. (2004): La sabiduría filosófica siguiendo las huellas de Santo Tomás, primera parte, Tucumán: UNSTA, Tema II. Esta capacidad contemplativa tiene para nosotros un aspecto, que llamamos "intuición conjetural" muy importante para el diálogo con el contexto de descubrimiento en las ciencias naturales; hemos expuesto este tema en (1993): Popper, búsqueda con esperanza, Buenos Aires: Editorial de Belgrano.

${ }^{21} \mathrm{ST}, \mathrm{I}, \mathrm{Q}, 87$ a $1 \mathrm{c}$.

22 ST, I, Q, 59, a. 1 ad 1.

${ }^{23}$ Toda la obra de Husserl está atravesada por una noción de inteligencia como teoría, contemplación, “ver" intelectual. Pero un lugar muy destacado ocupa la crítica al positivismo, que desde dicha noción de teoría, realiza en (1970) The Crisis of European Sciences and Trascendental Phenomenology, Northwesten University Press,.

${ }^{24}$ Ver al respecto Stein, E. (1994) : "La fenomenología de Husserl y la filosofía de Santo Tomás de Aquino”, en La pasión por la verdad, Buenos Aires, Bonum, (Introducción, traducción y notas del Dr. Andrés Bejas)

${ }^{25}$ ST, I, Q. 83, a. 1c.

${ }^{26}$ ST, I-II, Q. 10 a. 2c.

${ }^{27}$ Toda la praxeología de Mises presupone la acción libre e intencional. Un talón de Aquiles en el fundamento filosófico del libre albedrío puede implicar una crítica interna a Mises, como de hecho ha sucedido. Ver Crespo, R. (1998): La crisis de las teorías económicas liberales, Buenos Aires: Fundación Banco de Boston, cap. VII.

${ }^{28}$ Sobre todo en Introducción filosófica a Hayek y en la "Introducción" a Teoría e historia, op.cit. 
perspectiva de este ensayo implica todo lo contrario: si vamos a concebir al liberalismo clásico como la defensa política de la intimidad personal, es obvio que deberemos concentrar en la noción de persona todo el peso de nuestra argumentación. Por eso estamos recordando la inteligencia y el libre albedrío como las características antropológicas básicas de todo aquello que llamemos persona.

Si toda persona es inteligente y libre, toda persona vive bajo un orden moral, porque la adecuación de sus actos hacia su fin último pasa por la mediación de su libertad. No es esta última, como libre albedrío, la que determina su naturaleza y su fin último, pero sí aquello por lo cual puede la persona orientar "por sí misma" sus actos hacia su propio fin ${ }^{29}$.

Desde este último punto de vista, la verdad es primariamente una vivencia moral (a partir de ahora utilizaremos, de modo adicional, el método y cierto contenido fenomenológico). Dado el libre albedrío, la persona puede optar entre la sinceridad, como virtud moral, o por la mentira, como voluntad de engaño. Esto presupone, desde luego, y a la vez manifiesta, un intelecto que en su vida concreta y cotidiana puede distinguir la verdad del error, limitadamente, desde luego. La verdad puede ser, como reza la afirmación clásica, una adecuación de la inteligencia con la realidad, pero, salvando las dificultades del término "adecuación" ello presupone que la persona puede entender que "está" en un mundo real, y al estar en el mundo, puede manifestarlo, y de allí emana lingüísticamente una proposición verdadera. Por ejemplo, "estoy escribiendo un artículo" en un determinado contexto de pregunta y respuesta.

\section{Los deberes de la persona ante la verdad}

Dijimos que la verdad es ante todo una vivencia moral. La sinceridad presupone, ante todo, que se ha cumplido con el deber de buscar la verdad, y con el consiguiente deber de manifestar sin engaños la realidad vivida. Pero la verdad tiene otro esencial deber concomitante, esencial a nuestra argumentación: la no imposición de la verdad por la fuerza.

La verdad, como dijimos, surge de un "ver" intelectual, una captación del "estar en el mundo" que la persona, sólo por ser persona, es. La verdad se capta reflexivamente ${ }^{30}$, no es "otra" cosa al lado de la realidad que se vive, sino que es la misma realidad en cuando "vista y manifestada" por la persona. En este momento estoy escribiendo un artículo, y si alguien me pregunta qué estoy haciendo, digo "estoy escribiendo un artículo" y no necesito agregar "en verdad, en verdad os digo que" estoy escribiendo, excepto precisamente que el contexto me obligue a aclararlo.

Pero si por algún motivo la persona, a través de su inteligencia, no "ve" la verdad, (ni las verdades sencillas de su mundo cotidiano, ni otras que no sean tan inmediatas), entonces la verdad, por su misma

\footnotetext{
${ }^{29}$ ST, I, Q. 18 a. 3c.

${ }^{30}$ Ver Llano, A. (1984): Metafísica y lenguaje, Pamplona: EUNSA, Cap. II, punto 4.
} 
naturaleza, no puede imponerse por la fuerza (física o lingüística, como aclararemos después). La naturaleza misma de la verdad implica una relación entre inteligencia y realidad, una relación entre persona y mundo que nada tiene que ver con la coerción. Amenazas o premios externos a la misma naturaleza de las cosas pueden implicar que la persona "ceda" a la amenaza o premio, y "repita" bajo coacción, pero eso no es ver la verdad. Si algún lector considera que todo esto es obvio, la pregunta es si acepta los supuestos antropológicos que están detrás, o por qué, por ejemplo, casi todos los sistemas formales de enseñanza están basados bajo esas coerciones y repeticiones.

Dado que la naturaleza de la verdad se basa entonces en estas dos fuentes, esto es, mundo y persona, y dado que el deber ser se basa en el ser de las $\operatorname{cosas}^{31}$, entonces la verdad no debe imponerse por la fuerza. Tampoco, por ende, por medio de la fuerza "lingüística", esto es, por medio de actos del habla específicamente planeados para el engaño y el dominio del otro, pero ese tema lo debemos dejar para después por una cuestión de orden expositivo.

De lo cual se desprende un deber de justicia. El deber de no imponer la verdad por la fuerza, visto desde el "otro", es su derecho. Todo deber implica, por parte del "otro" el derecho a reclamar el cumplimiento del deber. Por ende, toda persona tiene derecho a que la verdad no le sea impuesta por la fuerza. Dicho de otro modo, toda persona tiene derecho a la ausencia de coacción sobre su propia conciencia, conciencia cuyo juicio singular y subjetivo juzga, precisamente, que tal o cual afirmación concreta es o no es una aplicación singular de la norma de sinceridad y no engaño. La conciencia puede ser errada, sí, y si una conciencia es errónea de modo culpable, el juicio corresponde sólo a Dios creador $^{32}$. La conciencia errónea obliga "per accidens"33, esto es, hasta que el error se corrige. Pero la persona no puede ser coaccionada a ver lo que no ve, precisamente porque, como dijimos, ello es contradictorio con su naturaleza intelectual. El derecho a la ausencia de coacción sobre la propia conciencia no es, por ende, un derecho al contenido específico de lo que la inteligencia ve como verdadero y la conciencia juzga que debe decir, sino un derecho a la ausencia de coacción, aunque el contenido sea materialmente falso y la conciencia, subjetivamente, sincera. Si el error es inculpable, o negligente, o si el error hubiera podido evitarse mediante una búsqueda sincera de la verdad, todo ello queda fuera de lo que una potestas humana pueda juzgar. En cualquier caso, se mantiene siempre el derecho a no ser coaccionado en la propia conciencia, y no es propio del ser humano juzgar con total certeza sobre la negligencia o no de la conciencia del otro.

${ }^{31}$ En Santo Tomás el deber ser es el mismo ser puesto en perspectiva de la causa final. Eso contradice obviamente la visión de Hume sobre esta cuestión. Es simplemente una incomunicabilidad de paradigmas: Hume niega la metafísica que Santo Tomás afirma.

${ }^{32}$ Ver Concilio Vaticano II, Gaudium et spes, 28.

${ }^{33}$ Santo Tomás, De Veritate, Q, 17, a. 4; ST, I-II, Q. 19 a 4, citado por Jesús García López en (1979): Los derechos humanos en Santo Tomás de Aquino, Pamplona: EUNSA. 


\section{La dimensión dialogal y co-personal del ser humano}

Hemos supuesto la inter-subjetividad del mundo de vida de Husserl ${ }^{34}$ como constitutiva de "lo" humano a nivel ontológico. Esto es, que el ser humano está constitutivamente en el "mundo" no como cosa física sino como conjunto de relaciones con los otros que constituyen la realidad a partir de la cual las cosas físicas son entendidas y por ende interpretadas ${ }^{35}$. Schutz, discípulo a la vez de Mises y Husserl, desarrolló este tema como fundamento de las ciencias sociales, pero en Husserl la inter-subjetividad es ontológica: si hay ser humano, hay mundo en el sentido referido.

Pero hay una dimensión de la intersubjetividad, que es constitutiva de la esencia humana en tanto sólo puede darse entre personas, pero no siempre éstas la llevan de la potencia al acto. El ser humano, porque es persona, puede abrirse a una relación de dominio estratégico del otro, o, al contrario, de comunicación o entendimiento que no quiera el dominio del otro sino el bien del otro. Esta diferencia entre dominio y comunicación constitute el eje central de la teoría dialógica de Habermas ${ }^{36}$, pero nosotros la estamos colocando en el contexto tomista anteriormente referido ${ }^{37}$. Un ser humano, precisamente porque tiene inteligencia y voluntad, puede conocer cuál es el bien del otro y desearlo, esto es, querer el bien del otro en tanto bien, sin que ello constituya parte de un plan que coloca al otro en una mera relación de medio para el sí mismo. Esto, que clásicamente se llama amistad, implica de por sí una dimensión comunicativa y dialogal para con el otro, porque en ese caso el lenguaje adquiere características de diálogo, de búsqueda del entendimiento con el otro. En la acción estratégica y en su correlato, esto es, en sus actos del habla estratégicos, el otro es visto como un mero medio para mis propios fines. Esta estrategia es obviamente oculta al otro para que tenga "éxito", y constituye por ende, casi siempre, un engaño. Si la estrategia es abierta, anunciada, se convierte en un juego compartido y pierde su carácter de dominio. Lo que Habermas no vio es que las relaciones comerciales son estrategias abiertas y en ese sentido dialógicas ${ }^{38}$.

En la comunicación con el otro, en cambio, se quiere el bien del otro como fin, no como mero medio para los propios fines. Esto es adecuado también al segundo imperativo categórico kantiano ${ }^{39}$ (nunca considerar al otro como medio sino siempre como fin) que el filósofo Karol Wojtyla considera

\footnotetext{
${ }^{34}$ De Husserl y la intersubjetividad, ver sobre todo The Crisis..... (op.cit); (1989) Ideas II, Kluwer Academia Publishers; (1986): Meditaciones cartesianas, Madrid: Tecnos; y (1994): Problemas fundamentales de la fenomenología, Madrid: Alianza.

${ }^{35}$ El mundo de vida de Husserl, como base para la interpretación, es utilizado por Gadamer para su propia hermenéutica. De ello, hemos hecho una interpretación conforme al realismo de Santo Tomás en Hacia una hermenéutica realista, en prensa.

${ }^{36}$ Sobre todo en (1987): Teoría de la acción comunicativa, Madrid: Taurus.

${ }^{37}$ En (2000) :"Intersubjetividad y comunicación”, Studium, Tomo IV, Fasc. VI, pp. 221-261.

${ }^{38}$ En ese sentido cabe relacionar el papel comunicativo del mercado (Hayek) con actos del habla perlocutivos con estrategia abierta y, por ende, comunicativos en sentido habermasiano.

${ }^{39}$ En su (1983): Fundamentación de la metafísica de las costumbres, Madrid: Espasa-Calpe.
} 
parcialmente coincidente con la ética cristiana ${ }^{40}$. Una persona no puede estar constitutivamente cerrada a su dimensión dialógica, aunque no actualice en su acción moral esta dimensión. En un experimento imaginario, en el cual una araña fuera dotada de inteligencia y voluntad, ella sería capaz, obviamente, de tomar conciencia de sí y de razonar instrumentalmente sus planes de dominio del otro, con la tela, de otro que es siempre su víctima, pero su inteligencia la haría concebir también la posibilidad de ayuda: podría concebir, aunque no lo llevara a la acción, la diferencia entre dominar con la tela o ayudar, perdonar; distinguir en el otro la relación ya de víctima, ya de amigo. En ese sentido, la persona, por su inteligencia y voluntad, no puede carecer de esa dimensión dialogal. Sólo por ser persona, una persona puede querer libremente el bien del otro. Una araña inteligente y libre destinada necesariamente al dominio de su víctima es una contradicción en términos.

Ahora bien, en la ley natural de Santo Tomás, el deber ser es el mismo ser "puesto en ejemplar" ${ }^{41}$, es la misma naturaleza de la persona destinada a su plenitud ontológica. Por ende, la dimensión dialogal de la persona, constitutiva de su esencia, aunque no sea llevada al acto, tiene el carácter de exigencia moral. La persona humana es constitutivamente dialogal y por ende debe serlo. La conclusión es que la persona humana se plenifica sólo en la amistad. Puede optar por no entrar jamás en relación de amistad con el otro, puede optar siempre por tener con los otros relaciones sólo instrumentales de dominio, pero en ese caso se está negado a sí misma su propia plenitud. En ese sentido la persona es co-personal, es un "ser-con-el-otro" no sólo ya como intersubjetividad ontológica, sino moral.

Por lo tanto, la indiferencia para con el otro no es el camino de la ética de la persona, sino al contrario: el cuidado, la preocupación, la ayuda para con el otro constituye el eje central de la vida moral de la persona. Toda la filosofía del diálogo de un Buber o un Levinás se encuentra con facilidad en la noción clásica de persona.

La dialéctica entre individuo y comunidad, desde este último punto de vista, se desvanece. La persona es siempre intersubjetiva, es siempre un nosotros. El punto es el enfoque ético que se da al nosotros. Si la persona instrumentaliza su relación con el otro, donde el otro queda anulado como un mero instrumento, estamos en un nosotros alienante, donde la relación es un "yo-eso". Si la persona saca de la potencia al acto sus capacidades constitutivas de amistad, estamos en un nosotros comunicante, donde la relación es un "yo-tú". La noción de fondo que se mueve aquí es la igual dignidad de las personas (igual dignidad fundada en la noción de Santo Tomás de inteligencia y voluntad pero complementaria, como hemos visto, con una noción kantiana de dignidad). La relación que yo tengo con un lápiz con el que escribo es correctamente una relación yo-eso; es un mero instrumento a mi servicio, y está bien que así sea. Por eso puedo establecer en "eso" una correcta relación de dominio. El lápiz ya

\footnotetext{
${ }^{40}$ En su libro (1994): Cruzando el umbral de la esperanza, Barcelona: Plaza y Janés, cap. 30.

${ }^{41}$ Debo esta expresión a la Dra. María Celestina Donadío Maggui de Gandolfi.
} 
no sirve y lo tiro. Hacer eso con una persona, en cambio, es atentar contra su dignidad de persona. Pero el paso adicional que estamos dando es que la relación éticamente adecuada con la persona no es una relación “yo-tú no molestes”, sino "yo-tú me importas porque eres un tú".

\section{Derecho a la intimidad y principio de no agresión}

Pero, ¿cómo se relaciona esto con lo anterior? Es hora de que las piezas encajen y que el punto de nuestro ensayo sea demostrado.

¿Cómo fundamentar en lo anterior un liberalismo clásico que todo lo que pretende es la limitación del poder? El discurso anterior, ¿no lleva precisamente a los autoritarismos basados en la "protección" del más débil?

No, y no sólo "no" porque el discurso anterior no sea contradictrio con un liberalismo clásico, sino que es su mejor fundamento.

Hemos planteado una relación de cuidado, de preocupación para con el otro como un imperativo moral de la persona. Pero esa relación presupone una relación de vecindad y no de invasión, esto es, presupone dos "yo" cada uno con una "esfera", con un círculo alrededor del yo tal que, si fuera "invadido” por la fuerza física o la dominación lingüística, impediría esa relación "yo-tú”.

Y es aquí donde debemos utilizar como premisas las conclusiones del punto 4.

La persona tiene un ámbito, un círculo que se expande a su alrededor, que podemos denominar "casa existencial" precisamente porque tiene inteligencia y voluntad. Por su inteligencia y voluntad, la persona ve o no ve la verdad, y toma decisiones libres, acertadas o no. Como dijimos en el punto 4, esa verdad no puede ser impuesta por la fuerza. Yo, con respecto al tú, puedo y debo entrar en diálogo, esto es, en un tipo de lenguaje que abra mi propio horizonte, clarifique mis intenciones y exponga al otro mis preocupaciones por él, pero, dada la propia naturaleza racional del otro, no lo puedo forzar ni engañar. Su yo más profundo, aquello que es fuente de su inteligencia y voluntad, es su casa; como toda casa, tiene una puerta, la cual no debe ser derribada por la fuerza, so pena de cambiar la relación yo-tú a una relación de dominio, de destrucción de la casa (la propiedad) del otro.

Por lo tanto, dado que "yo" tengo el deber de establecer con el otro una relación dialogal, "el otro" tiene un derecho a la intimidad, que no es más que el reclamo potencial de mi deber de no destruir la puerta de su casa existencial. Es el mismo derecho a la intimidad del punto 4 pero mostrado en relación con la condición dialogal de la persona. La conciencia del otro no debe ser invadida, so pena de anular la relación dialogal. La tentación de anular la intimidad del otro viene dada precisamente, a veces, por el deseo de protección del otro, sin ver que el "cuidado" mutuo de la relación yo-tú excluye, por su propia naturaleza, la fuerza o planes estratégicos de dominación del otro. 
El resultado de esto es una re-elaboración del principio libertario de no agresión, en armonía con Dios, que en el punto 2 habíamos establecido como "El Señor", el dueño, y la relación dialogal con el otro. Dado el derecho a la intimidad, yo no soy el dueño de otro. Yo debo radicalmente no invadir, no coaccionar la conciencia del otro precisamente porque en una relación dialogal, ni el yo es propietario del tú, ni el tú propietario del yo, y, a la vez, ni el tú ni el yo son dueños absolutos de sí: Dios es el dueño. O sea: el yo no es el dueño de sí pero radicalmente no es el dueño del otro. El principio de no agresión sobre el otro no se funda, por ende, en una propiedad absoluta del yo sobre sí, sino en reconocer en el otro su condición de persona y respetar consiguientemente su derecho a la intimidad.

\section{Resultados jurídicos y políticos}

Como hemos visto, hemos definido un derecho a la intimidad como "derecho a la ausencia de coacción en el ámbito de la propia conciencia", y hemos visto que: a) ese ámbito está definido por la esfera o círculo del yo, de donde provienen la inteligencia y la voluntad; b) que ese principio es equivalente al principio de no agresión libertario, sin que ello implique: a) que uno sea dueño absoluto de sí; b) que Dios no sea nuestro dueño; c) que ello sea contradictorio, sino todo lo contrario, con el cuidado y protección hacia el otro; d) ninguna contradicción con la noción de ley natural de Santo Tomás.

Ese derecho a la intimidad tiene un resultado jurídico que cubre las principales preocupaciones del liberalismo clásico como sistema constitucional de protección de una libertad negativa como Hayek la concibe. Se trata del derecho a la ausencia de coacción sobre la conciencia y, consiguientemente, sobre todas aquellas acciones que no dañen a un tercero, que jurídicamente se llaman "privadas". Esta extensión jurídica tiene su fundamento, no sólo en la antropología filosófica del ser humano como co-personal, sino también en la distinción entre ley humana y ley natural que hace Santo Tomás. Sin ninguna contradicción, sino al contrario, con que toda ley humana tenga un efecto "educativo" ${ }^{42}$, Santo Tomás afirma luego: “... la ley humana se establece para una multitud de hombres, en la cual la mayor parte no son hombres perfectos en la virtud. Y así, la ley humana no prohíbe todos los vicios, de los que se abstiene un hombre virtuoso; sino sólo se prohíben los más graves, de los cuales es más posible abstenerse a la mayor parte de los hombres, especialmente aquellas cosas que son para el perjuicio de los demás, sin cuya prohibición la sociedad no se podría conservar como son los homicidios, hurtos, y otros vicios semejantes" ${ }^{\prime 4}$. Este párrafo, de una enorme riqueza que ya en otra oportunidad hemos comen$\operatorname{tado}^{44}$, muestra la imposibilidad antropológica de una perfección lograda por medio de la fuerza legal, lo cual es plenamente coherente con la intimidad como la hemos definido, porque el yo, dado que es inteligente y libre, se perfecciona cuando por sí mismo se mueve hacia su fin, y no por medio de la

\footnotetext{
${ }^{42}$ I-II, Q. 92, a. 2c.

${ }^{43}$ I-II, Q. 96, a. 2c

${ }^{44}$ En El humanismo del futuro, op.cit., cap. 1.
} 
amenaza legal. Esto supone, sí, que la ley humana, dado que no debe ser contradictoria con la ley natural, exige no atentar contra derechos de otros, y esa exigencia, como diría Hayek, es parte de un marco cultural de tradiciones que "suple" lo que un conocimiento disperso no puede razonar "totalmente". Pero la decisión de hacer algo moralmente bueno no pasa por el temor servil ante la ley humana. El que decide no realizar tal delito sólo por el temor al castigo de la ley humana, es casi como si ya lo hubiera realizado en su interior.

Acción "privada" no significa, por ende, reiterar una dialéctica individuo/comunidad que hemos evitado en todo el planteamiento. Privada significa que emerge de la propia conciencia, errónea o no, sin coaccionar la conciencia de terceros por medio de coacción física. Privado es todo aquello que no es ilegal. Lo privado se abre entonces a la "vida privada" no como vida no comunitaria, sino como una vida abierta a un sin fin de relaciones intersubjetivas comunicantes, abiertas a la preocupación y al cuidado del otro, y fuera, coherentemente, de todo margen de coacción estatal. Las acciones "privadas" incluyen por ende, aunque no necesariamente en todos los casos, todas aquellas acciones realizadas bajo el derecho a la libre asociación. Lo privado no es "individualista" sino aquello protegido contra la interferencia indebida de otro ser humano que radicalmente no es el dueño de nadie. Por eso el artículo 19 de la Constitución Argentina de 1853 se adecua notablemente a todo lo que estamos diciendo: "Las acciones privadas de los hombres que de ningún modo ofendan al orden y a la moral pública, ni perjudiquen a un tercero, están sólo reservadas a Dios, y exentas de la autoridad de los magistrados".

Este es el sentido iusnaturalista y "comunitario" del famoso harm principle de J. S. Mill. En el contexto en el que lo estamos planteando, es un principio jurídico, esencial para el límite preciso, o lo más preciso posible, a la coacción indebida del estado. No significa un individualismo que no tenga en cuenta el aspecto co-personal del ser humano, y menos aún un principio de neutralidad estatal sobre valores morales. Qué significaba en J. S. Mill no es objeto de nuestro ensayo. Simplemente estamos seguros de no estar haciendo una "decodificación aberrante" de las implicaciones jurídicas del principio. Porque es claro que, dado precisamente el carácter co-personal de la persona humana, toda acción moralmente mala daña a todas las interacciones humanas en su conjunto. Pero otra acción mala, y muy mala, sería, como vimos, violar el derecho a la intimidad personal. Y el harm principle es el límite jurídico preciso (o al menos, el más preciso hasta el momento) para no dar el paso al totalitarismo con la excusa de impedir el mal. Las acciones privadas malas moralmente que no violen derechos de terceros no deben ser impedidas (tolerancia) porque el derecho a la intimidad no se basa en el contenido de la acción, sino en que la verdad no puede ser impuesta por la fuerza al yo. Hacerlo implicaría un mal social mucho peor que el que se quiere impedir: el mal social de que todos se estén persiguiendo los unos a los otros, sin límite, sin debido proceso, llevando a la sociedad humana a la involución de un caos de concepciones de vida bélicamente interpuestas.

Todo lo que estamos diciendo es obvio por un lado, pero conflictivo por el otro, dependiendo del paradigma desde donde se mire. Aquellos liberales clásicos que piensen que su liberalismo clásico está 
sólidamente pertrechado en la desconfianza hacia un sistema metafísico que postule una moral personal “objetiva” mirarán con asombro nuestra interpretación comunitaria, co-personal y iusnaturalista del harm principle de Mill. Aquellos que critiquen al liberalismo clásico como un individualismo que no tiene en cuenta ni la moral clásica ni el aspecto típicamente comunitario y co-personal del ser humano, tendrán el mismo asombro frente a nuestra defensa jurídica del liberalismo clásico.

Es que el liberalismo clásico fue y sigue siendo, en autores como Mises y Hayek, (y en clásicos anteriores como Locke, Montesquieu, Madison, Adams, Jay, Jefferson, Tocqueville, etc.) una técnica jurídica de limitación al poder, más que una doctrina filosófica específica. Pero la preocupación por limitar al poder viene dada por el firme convencimiento, moral, de la importancia de los derechos individuales "frente" al poder. De esos derechos, estamos privilegiando el derecho a la intimidad, tentados tal vez de montar un sistema racionalista, como lo hace un libertario como Rothbard, donde la propiedad de sí mismo y el principio de no agresión son los axiomas de un sistema de derechos que finalmente no son más que teoremas del mismo axioma. Y, en cierto sentido, ello podría hacerse "in abstracto". Del derecho a la ausencia de coacción sobre la propia conciencia derivan derechos negativos clásicos tan importantes como libertad religiosa, de expresión, de enseñanza, de emigración, de asociación, etc. A su vez, hemos dicho que esa conciencia es el ámbito donde se mueven la inteligencia y voluntad de la persona, esto es, del yo, y por ende esta antropología filosófica da pie a una "propiedad" del yo en el sentido de que el otro no es dueño de ningún yo, y por ende esto da origen a una propiedad con todas sus consecuencias para el tema del libre mercado. Pero en concreto, pretender que una deducción tal pueda tener en cuenta todas las circunstancias de la historia, es constructivismo como Hayek lo denunció $^{45}$. No sabemos lo que no sabemos, y por ende hay posibilidades concretas de aplicación histórica de estos mismos principios sencillamente impredecibles. Un esquema evolutivo como el de Hayek ${ }^{46}$, donde los derechos individuales se van viendo en concreto, en la evolución de un orden espontáneo, es una consecuencia del reconocimiento de nuestra ignorancia en ciencias sociales. Lo que hoy es liberal puede ser autoritario en el futuro, y lo que ayer fue, a nuestros ojos presentes, autoritario, pudo haber sido un paso hacia el liberalismo de hoy. Pero la preocupación teorética por la intimidad personal implicará un "estar alertas" a expandir permanentemente el paradójico "cuidado" de la libertad personal. Denuncias como las de Feyerabend ${ }^{47}$, sobre la unión entre ciencia y estado, que evidentemente se adelantan a su época, son un ejemplo de lo que estamos diciendo. Pero, a la vez, ello quita a este principio libertario todo deje de revolución violenta, es, al contrario, un llamamiento a la evolución progresiva y, a la calma en debates que "in abstracto" no podemos solucionar de una vez y para siempre, al margen de la

\footnotetext{
${ }^{45}$ Sobre todo en (1979): The Counter-Revolution of Science, Liberty Press.

${ }^{46}$ Sobre todo en Los fundamentos de la libertad, op.cit., cap. XI.

${ }^{47}$ Sobre todo en (1981): Tratado contra el método, Madrid: Tecnos, cap. 18, y (1992): Adiós a la razón; [versión inglesa], Madrid: Tecnos.
} 
historia. "El" liberalismo no es "la" respuesta automática a todos los social issues que preocupan actualmente. Es una tendencia, una visión prospectiva y retrospectiva de la historia, es un programa de investigación ${ }^{48}$ : no es "la" solución que "los malos o tontos" no quieren/no pueden, "ver".

\section{Un tema cultural: la racionalización del mundo de vida y la pérdida de intimidad}

El "olvido de la intimidad" como clave de un liberalismo clásico ha retroalimentado, tal vez, que en la última etapa de la escuela de Frankfurt (Habermas) se criticara muy intensamente la racionalización del mundo de vida ${ }^{49}$, esto es, la invasión de esferas íntimas de la vida humana como resultado del avance de la "racionalidad instrumental" sobre la relación con el otro. Por un lado, es verdad que una racionalidad instrumental (esto es, la sola consideración de algo como mero medio respecto de un fin) es incompatible con la ética que estamos planteando; por el otro, no es verdad que un liberalismo clásico, como lo entienden Mises y Hayek, conduzca a la invasión del mundo de la vida; pero sin embargo los debates del liberalismo clásico parecen despreocupados por las críticas de la escuela de Frankfurt a la racionalidad instrumental. En este ensayo estamos tratando de dar vuelta esa tendencia, y en un ensayo reciente $^{50}$ hemos intentado demostrar que las críticas de Hayek al racionalismo constructivista y las de Feyerabend al cientificismo son muy similares a las críticas de la escuela de Frankfurt a la racionalización del mundo de vida y a la dialéctica del iluminismo, con la ventaja de que dichos autores no caen en la "dialéctica de la crítica a la dialéctica del Iluminismo": tomar a Marx como base para dicha crítica, por cuanto el resultado sólo puede ser incurrir en un nuevo tipo de coacción y violencia.

Todo lo cual es introductorio para decir que una comunidad de seres humanos libres, sobre la base de un gobierno limitado y la máxima expansión posible del mercado libre, es una comunidad "nopolitizada" donde la esfera de lo privado se expande lo máximo posible, y lo público se reduce a un mínimo indispensable. Muchas críticas al liberalismo clásico parten de cierta nostalgia de ciertas polis griegas, donde la máxima virtud del ciudadano consistía en la participación en una esfera "pública" donde se decidían conjuntamente los problemas de la comunidad. La libertad "de los modernos", en cambio, estaría infectada del individualismo indiferente "al otro" donde cada uno se sumerge en su propio proyecto de vida y se olvida de "la política y el bien común". Desde la perspectiva que estamos proponiendo, ello no es verdad ${ }^{51}$.

${ }^{48}$ En el clásico sentido de I. Lakatos (1983): La metodología de los programas científicos de investigación, Madrid: Alianza.

${ }^{49}$ Sobre este tema, ver Elizalde, L. (2003): Comunicación de masas y espacio público en Habermas, Buenos Aires: Austral.

50 "Feyerabend y la dialéctica del Iluminismo", Studium, en prensa.

${ }^{51}$ Ver al respecto el clásico ensayo de Contant sobre la libertad de los antiguos comparada con la libertad de los modernos (ver www.uark.edu/depts/comminfo/cambridge/ancients.htm), así también como Fustel de Coulanges (1994): La ciudad antigua, México: Porrúa, cap. XVIII. Agradecemos a Constanza Mazzina el habernos destacado la importancia de estas dos clásicas referencias. Esto no implica que adherimos a la tesis de la dicotomía y dialéctica total entre ambos tipos de ciudades y libertades; al contrario, nuestra visión de la historia política es más bien evolutiva, como en Hayek. Simplemente recordamos esta cuestión por lo que consideramos una nostalgia de las polis griegas que peca de cierta ingenuidad. 
Ya hemos dicho que una vida vivida en un mundo donde la intimidad se respete, es una vida abierta al nosotros comunicante, desde el nosotros ontológico de la inter-subjetividad. Ello incluye, claro está, la tolerancia (como resultado del respeto a la intimidad) de actitudes moralmente indiferentes hacia el otro, pero no es eso la base de la vida de la intimidad. La vida privada, que emerge de la intimidad, es, como vimos, una vida donde se despliegan los derechos personales, y en ese sentido una vida humana abierta a la infinita posibilidad de asociaciones intermedias y de proyectos personales que incluyen relaciones con el otro, ya sea comerciales y-o de amistad donde, como dice Huerta de Soto ${ }^{52}$, se produce un "big-bang" social de despliegue de proyectos que en caso de autoritarismo están cortados, como una semilla encarcelada que no puede germinar ${ }^{53}$. Las relaciones entre los seres humanos son entonces como deben ser: de respeto y-o de amistad, nunca de coacción. Esta última se reserva, precisamente, a la esfera de protección jurídica de la intimidad, donde, si el esquema es liberal clásico, la coacción estaría sólo justificada en un esquema constitucional donde la famosa "fuerza pública" se aplica sólo a la protección jurídica de los derechos personales que sean violados. Lo político, en ese sentido, no llena la vida social, sino que se reduce a un mínimo. Loable sea la vocación de aquél que quiera dedicarse a esa esfera de lo público, pero que no vea a los demás como aquellos que no se dedican a la vida en comunidad: al contrario, sus vidas son vidas en comunidad sin coacción, vidas abiertas al nosotroscomunicante, donde el nosotros-alienante es tolerado si se produce en una relación intersubjetiva sin coacción física, y prohibido si llegare a significar la coacción del tirano sobre la masa alienada.

En este sentido, las nociones de "público, privado e íntimo" pueden ser redefinidas. Hay una noción de "público" que se indentifica con lo "gubernamental", que como vimos significa el ámbito de los tres poderes de una democracia constitucional clásica. Hay un ámbito de lo privado que a veces se identifica con las manifestaciones "visibles" de las decisiones privadas, como por ejemplo estar caminando por la calle con un amigo. Esa esfera depende de la extensión de los bienes públicos. Pero a su vez hay otra noción de lo "público" que tiene que ver precisamente con esa vida íntima extendida en las asociaciones intermedias y en la vitalidad de su expresión. Es en ese sentido que, por ejemplo, la religión fue en los EE.UU. un ámbito "público-no estatal" cosa que cuesta entender si la disyuntiva es sólo "gubernamental vs. íntimo".

La vida íntima, por ende, es privada y comunitaria al mismo tiempo, en el sentido de que no es gubernamental. La diferencia habitual entre lo íntimo y lo privado pasa en ese caso por aquello que sale de las puertas del hogar, cosa que genera la zona gris de la moral pública en la medida que haya bienes públicos estatales. Pero, como vemos, en nuestro esquema la diferencia básica entre la vida íntima, por un lado, que es "comunitaria por naturaleza" y la vida gubernamental, por el otro. Esta última "debe"

\footnotetext{
${ }^{52}$ En su libro (1994): Estudios de Economía Política, Madrid: Unión Editorial, cap. 1.

${ }^{53}$ Muy reducidos en caso de autoritarismo, y directamente cortados en caso de autoritarismo.
} 
ser reducida lo máximo posible, en la medida que la coacción es la última alternativa de relación entre seres humanos racionales. Ese es todo el sentido del intento de Hayek de "bajar a la política de su pedestal" 54 , creemos que casi no comprendido. Se ve con desprecio, a veces, al que "no se quiere dedicar a la política" (mezclado con el inconsistente desprecio a lo político como lo corrupto) como si "la comunidad" no le importara, sin advertir que la política, como la hemos definido, es el ámbito gubermanetal, y en ese sentido el círculo "protector jurídico" de los derechos individuales que se despliegan en la vida comunitaria. La importancia de "lo político" va creciendo en modo proporcional a los hábitos culturalmente autoritarios de una sociedad, donde entonces "el gobernante" tiene cada vez mayor importancia sobre decisiones privativas de la conciencia del otro (precisamente como no debe ser), y decide sobre ella. Feliz, en cambio, sea el humilde granjero norteamericano que no se acuerda del nombre del gobernador de su estado. Eso es algo que las culturas latinoamericanas, lamentablemente drogadas con el autoritarismo, no pueden entender.

Una vida íntima es una vida en paz, llena de sencillas cotidianidades indiferentes a oídos autoritarios, que han dibujado una historia de héroes, de caudillos, de militares, de gobernantes, de dinastías. Una vida íntima es la historia de amigos, de inventores, de comerciantes, de empresarios, de científicos, filósofos, artistas, de novios, de esposos, de amores imposibles, de ilusiones y desilusiones: de aquellos que al no querer, precisamente, salvar al mundo, lo hicieron sin intentarlo ${ }^{55}$.

\section{“Aquí no"}

Hemos dicho que la intimidad es la casa existencial. Permítaseme entonces citar un ensayo en el cual esta imagen tiene un giro adicional.

Se trata del artículo "No, dijo William gravemente, aquí no", de Luis Jorge Zanotti56. El artículo resume un aspecto de una novela de Evelyn Waugh, donde su protagonista, William Boot, es un viejo, noble y tradicional aristócrata, que logra, casi sin proponérselo, un contrato importante con una empresa periodística, sin salir, sin embargo, de sus costumbres ni del viejo castillo que habita -su casa- junto con su humilde familia y unos pocos empleados. Sucede entonces lo previsible: William se ve en la difícil circunstancia de tener que invitar a comer al dueño de la firma con quien ha firmado tan importante contrato. William afirma con toda sencillez que a la cena asistirán, además, "Nannie Blogs y Nannie Prince", a lo cual un empleado del dueño de la firma objeta que la presencia de esas damas no es tan

\footnotetext{
${ }^{54}$ Sobre este tema, ver Martínez-Amador, David (2002): "F.A. Hayek, su visión de la ciencia política: derribar a la política de su pedestal", Laissez-Faire, núm. 16/17.

${ }^{55}$ Ver, al respecto, el diálogo entre el médico y el alcalde en la película Cristo se detuvo en Eboli, de Francesco Rosi.

${ }^{56}$ En Zanotti, Luis J. (1994) : La hora de encontrarse a sí mismo, Buenos Aires: Editorial de Belgrano. Sobre la obra completa de Luis J. Zanotti ver www.luiszanotti.com.ar.
} 
importante como la de su encumbrado jefe. Y entonces William contesta “No. Aquí no". Transcribo entonces literalmente lo que sigue:

“'Aquí, no', dijo William gravemente. Aquí es la casa, el hogar, la familia; es la vida propia, única, irrepetible; es el templo amurallado por la argamasa de la civilización occidental en el que encuentra su asiento principal la libertad del hombre, del hombre concreto, de cada ser humano con su rostro, su cuerpo, su sangre... y su cuarto.

Ante ese templo se detienen los jerarcas del mundo y los poderes de cualquier clase. La autoridad de los soberanos concluye ante su puerta. De paredes adentro, la conciencia de cada hombre rinde cuentas sólo a Dios. ¿Quiénes son Nannie Bloggs, Nannie Price? No interesa demasiado explicarlo en detalle. Son la familia de William Boot, son su casa, su hogar heredado, su vida interior. Podrían ser su mujer, o sus hijas, o un par de tías viejas, o un cuarto con libros, o una sala con muebles queridos, o un jardín cultivado con sus manos. Son, en fin, el reducto del individuo transformado en persona, en un hombre libre que puede decir que no ante todos los poderes de este mundo.

Por eso la respuesta es inapelable y Mr. Salter debe retirarse. Nadie puede negar la importancia, el poder o la gloria de los grandes del mundo. Pero 'aquí' dos viejecitas son más importantes. Porque una vez que traspongo la puerta de mi hogar, nada, absolutamente nada del mundo exterior puede ser suficientemente poderoso como para entrar en él y violentarlo.

Poco más o menos, he ahí la base de la cultura judeo-heleno-cristiana a la cual pertenecemos. El hombre es un ser en relación directa y personal con Dios; es un ser libre; es un ser cuya dignidad es suprema.

Algo de todo esto late en la fórmula del artículo 19 de la Constitución nacional, también un modelo de economía de lenguaje en el campo filosófico y político: 'Las acciones privadas de los hombres que de ningún modo ofendan al orden y a la moral pública, ni perjudiquen a un tercero, están sólo reservadas a Dios, y exentas de la autoridad de los magistrados'.

Sepamos custodiar este legado de Occidente que es la libertad del individuo frente a los esfuerzos que los totalitarismos y los pretendidos socialismos benefactores, con excusas variadas, pretenden sepultar y ya han sepultado en muchos lugares de la tierra.

Porque, en última instancia, nada puede ser más importante. Y si de mi salvación eterna se trata, es un asunto que compete sólo a mí, de puertas adentro. Frente a cualquier solicitud que del mundo pueda llegarme, frente a cualquier reclamo que en nombre de los poderes de este mundo pueda hacérseme, no será malo acordarse de la respuesta de William Boot cuando se le alegó que un gran personaje era, sin duda, más importante que dos ancianas familiares de su propia casa: 'No, dijo William gravemente. Aquí, no'”57.

Vamos a adelantarnos popperianamente a la objeción que recibiremos de algunos. Me dirán que Luis J. Zanotti está pensando en hombres honorables, donde la puerta de su hogar representa la bondad de su vida, puerta que obviamente no debe ser derribada por diversas prepotencias. Pero no todos son William; al contrario, de lo que se trata es de degeneraciones morales aberrantes que deberían ser le-

\footnotetext{
${ }^{57}$ Op.cit, p. 103.
} 
gítimamente prohibidas, y que todo este ensayo está "defendiendo" en nombre de la intimidad personal....

He allí el punto de quiebre entre dos actitudes límite ante la imperfección de la vida social. No habitamos la ciudad de Dios, habitamos la ciudad del hombre, tan inexorablemente atravesada por la imperfección del hombre como el hombre mismo. Quien no termine de admitir la perfección de la tolerancia de la imperfección, terminará en la imperfección aberrante de quienes invaden las casas de los otros, queriendo, vanamente, convertirlas en perfectas por la fuerza.

Ya mucho más, no se puede decir. La ciudad del hombre ha sido, es y será esencialmente imperfecta. En medio de los avatares de la historia, algunos han señalado un deber: respeta al otro, no lo invadas. Eso, sólo eso, en medio de las guerras que siguen, ¿no es ya soñar demasiado? Quienes, tan molestos por la imperfección del otro, sueñan con algo más allá de eso, han pasado de los nobles sueños a las utopías más ingenuas y, por lo tanto, más violentas ${ }^{58}$.

\section{Referencias bibliográficas}

Libros:

- Crespo, R. (1998): La crisis de las teorías económicas liberales, Buenos Aires: Fundación Banco de Boston.

- Elizalde, L. (2003): Comunicación de masas y espacio público en Habermas, Buenos Aires: Austral.

- Feyerabend, P.K. (1981): Tratado contra el método; Madrid: Tecnos.

- Feyerabend, P.K. (1992): Adiós a la razón; [versión inglesa], Madrid: Tecnos.

- Fustel de Coulanges (1994): La ciudad antigua, México: Porrúa.

- García López, J. (1979): Los derechos humanos en Santo Tomás de Aquino, Pamplona: EUNSA.

- Hayek, F. A. von (1975): Los Fundamentos de la Libertad, Madrid: Unión Editorial.

- Hayek, F. A. von (1979): The Counter-Revolution of Science, Liberty Press.

- Hayek, F. A. von (1994): Estudios de Economía Política, Madrid: Unión Editorial.

- Husserl, E. (1970): The Crisis of European Sciences and Trascendental Phenomenology, Northwesten University Press.

- Husserl, E. (1989): Ideas II, Kluwer Academia Publishers.

- Husserl, E. (1986): Meditaciones cartesianas, Madrid: Tecnos.

\footnotetext{
${ }^{58}$ Al respecto ver Popper, K. (1983): “Utopía y violencia”, en Conjeturas y refutaciones, Paidós.
} 
- Husserl, E. (1994): Problemas fundamentales de la fenomenología, Madrid: Alianza.

- Juan Pablo II: Enc.. Fides et ratio.

- Juan Pablo II (1994): Cruzando el umbral de la esperanza, Barcelona: Plaza y Janés.

- Kant, I. (1983): Fundamentación de la metafísica de las costumbres, Madrid: Espasa-Calpe.

- Lakatos, I. (1983): La metodología de los programas científicos de investigación, Madrid: Alianza.

- Llano, A. (1984): Metafísica y lenguaje, Pamplona: EUNSA.

- Mill, J.S. (2001): On Liberty, en Polanco, Moris: 100 Books Of Philosophy, CD, Guatemala.

- Mises, L. von (1977): Liberalismo, Madrid: Unión Editorial.

- Mises, L. von (2003): Teoría e Historia, Madrid: Unión Editorial.

- Popper, K. (1971): The Open Society and its Enemies, Princeton University Press.

• Popper, K. (1983): “Utopía y violencia”, en Conjeturas y refutaciones, Paidós.

- Rawls, J. (1993): Political Liberalism, Columbia University Press.

- Rawls, J. (1999): The Law of Peoples, Harvard University Press.

- Rawls, J. (1971): A Theory of Justice, Harvard University Press.

- Rothbard, M.N. (1985): For a New Liberty, Fox \& Wilkes.

- Rothbard, M.N. (1998):The Ethics of Liberty, New York University Press.

- Sciacca, M.F. (1954): Historia de la filosofía, Barcelona: Luis Miracle.

- Stein, E. (1994): "La fenomenología de Husserl y la filosofía de Santo Tomás de Aquino", en La pasión por la verdad, Buenos Aires: Bonum. (Introducción, traducción y notas del Dr. Andrés Bejas)

- Tomás de Aquino (1963): Summa Theologiae, Torino: Marietti.

- Zanotti, Luis J. (1994): La hora de encontrarse a sí mismo, Buenos Aires: Editorial de Belgrano.

- Zanotti, G. (1989): El humanismo del futuro, Buenos Aires: Editorial de Belgrano.

- Zanotti, G. (2003): Introducción filosófica a Hayek, Guatemala/Madrid: Universidad Francisco Marroquín/Unión Editorial.

- Zanotti, G. (2003): Filosofía para filósofos, Madrid: Unión Editorial.

- Zanotti, G. (1993): Popper, búsqueda con esperanza, Buenos Aires: Editorial de Belgrano. 
Artículos:

- Martínez-Amador, David (2002): “F.A.Hayek, su visión de la ciencia política: derribar a la política de su pedestal”, Laissez-Faire, núm. 16/17.

- Zanotti, G. (2004): "Igualdad y desigualdad según desiguales paradigmas", Empresa y Humanismo, Vol. VII, núm. 2, pp. 259-254.

- Zanotti, G. (1999): “Karl Popper: antes y después de Kyoto”, Arbor núm. 642. pp. 229-243.

- Zanotti, G. (2001): “La ley natural, la cooperación social y el orden espontáneo", Revista de la Facultad de Derecho, Universidad Francisco Marroquín, núm. 19, pp. 117-122.

- Zanotti, G. (2000): En “Intersubjetividad y comunicación”, Studium, Tomo IV, Fasc. VI, pp. 221-261. 